(W)

Check for

Cite as

Nano-Micro Lett.

(2021) 13:170

Received: 30 April 2021

Accepted: 10 July 2021

Published online: 9 August 2021

(C) The Author(s) 2021

\section{Dendrite-Free and Stable Lithium Metal Battery Achieved by a Model of Stepwise Lithium Deposition and Stripping}

Tiancun Liu ${ }^{1}$, Jinlong Wang ${ }^{1}, \mathrm{Yi} \mathrm{Xu}^{1}$, Yifan Zhang ${ }^{1}$, Yong Wang ${ }^{1,2} \bowtie$

\title{
HIGHLIGHTS
}

- A facile method is adopted to obtain cucumber-like lithiophilic composite skeleton.

- Massive lithiophilic sites in cucumber-like lithiophilic composite skeleton can promote and guide uniform Li depositions.

- A unique model of stepwise Li deposition and stripping is determined.

ABSTRACT The uncontrolled formation of lithium (Li) dendrites and the unnecessary consumption of electrolyte during the Li plating/stripping process have been major obstacles in developing safe and stable Li metal batteries. Herein, we report a cucumber-like lithiophilic composite skeleton (CLCS) fabricated through a facile oxidationimmersion-reduction method. The stepwise Li deposition and stripping, determined using in situ Raman spectra during the galvanostatic Li charging/discharging process, promote the formation of a dendrite-free $\mathrm{Li}$ metal anode. Furthermore, numerous pyridinic $\mathrm{N}$, pyrrolic $\mathrm{N}$, and $\mathrm{Cu}_{\mathrm{x}} \mathrm{N}$ sites with excellent lithiophilicity work synergistically to distribute Li ions and suppress the formation of Li dendrites. Owing to these advantages, cells based on CLCS exhibit a high Coulombic efficiency of $97.3 \%$ for 700 cycles and an improved lifespan of $2000 \mathrm{~h}$ for symmetric cells.

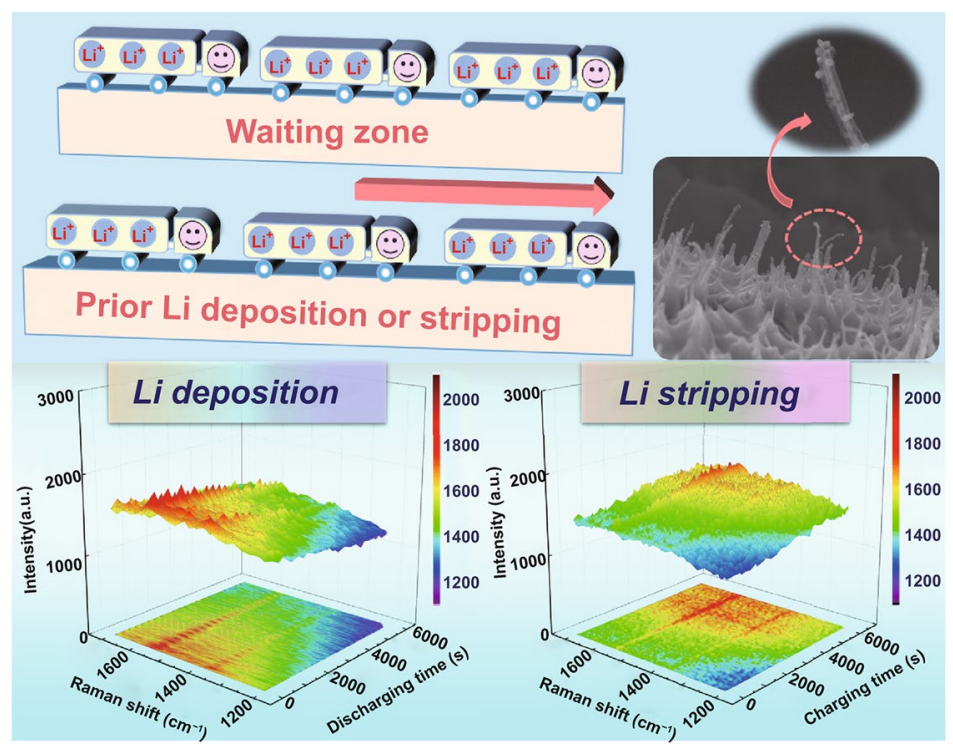
The full cells assembled with $\mathrm{LiFePO}_{4}$ (LFP), $\mathrm{SeS}_{2}$ cathodes and CLCS@Li anodes demonstrate high capacities of $110.1 \mathrm{mAh} \mathrm{g}^{-1}$ after 600 cycles at $0.2 \mathrm{~A} \mathrm{~g}^{-1}$ in CLCS@LilLFP and $491.8 \mathrm{mAh} \mathrm{g}^{-1}$ after 500 cycles at $1 \mathrm{~A} \mathrm{~g}^{-1}$ in CLCS@LilSeS 2 . The unique design of CLCS may accelerate the application of Li metal anodes in commercial Li metal batteries.

KEYWORDS Lithiophilic skeleton; Stepwise Li deposition and stripping; Dendrite suppression; Lithium metal battery; Electrochemical properties

Yong Wang, yongwang@shu.edu.cn

1 Department of Chemical Engineering, School of Environmental and Chemical Engineering, Shanghai University, 99 Shangda Road, Shanghai 200444, People's Republic of China

2 Key Laboratory of Organic Compound Pollution Control Engineering (MOE), 99 Shangda Road, Shanghai 200444, People's Republic of China 


\section{Introduction}

Lithium (Li) metal anodes exhibit a high theoretical capacity $\left(3860 \mathrm{mAh} \mathrm{g}^{-1}\right)$ and the lowest reduction potential $(-3.04 \mathrm{~V}$ vs. SHE) among next-generation high-energy systems to enhance the Li-ion battery [1-3]. However, issues such as the fatal growth of dendritic $\mathrm{Li}$, inhomogeneous $\mathrm{Li}$ deposition, and additional electrolyte consumption during the Li plating/ stripping process result in low Coulombic efficiency (CE), quick capacity decay, and the internal short circuit of the cell. These critical challenges need to be overcome effectively for the practical utilization of Li metal anodes [4-6]. The primary concern is restraining the production and growth of Li dendrites. Recent literature has yielded several effective methods such as constructing an artificial solid electrolyte interface (SEI) with high stiffness [7-10], designing functional separators [11-13], and modifying the electrolyte by adding additives [14-16] to suppress the growth of Li dendrites. Consequently, these solutions have improved the cycling stability and prolonged the lifespan of the Li metal anode.

Constructing functional current collectors is another effective approach to achieve dendrite-free Li metal anodes. The Chazalviel diffusion model suggests that decreasing the effective electrode current density extends the Sand's time, i.e., initial time for the growth of Li dendrites [17-19]. Consequently, the increase in the specific surface area reduces the local current density of the electrode while further suppressing the generation of Li dendrites. Several substrates with high specific surface areas have been designed as containers for the deposited metallic $\mathrm{Li}$ to produce dendrite-free Li metal anodes [20-24]. Additionally, lithiophilic sites in the substrate effectively disperse $\mathrm{Li}$ ions, thereby reducing the Li nucleation barrier and guiding uniform Li deposition. Some inorganic components such as heteroatom-doped carbon [25-27], metals and their derivatives [28-35] along with unique organic materials [36-39] possess excellent lithiophilicity to promote homogeneous $\mathrm{Li}$ deposition and growth. Therefore, an ideal current collector must possess abundant lithiophilic groups to impart substantial lithiophilicity.

Herein, we propose a distinct cucumber-like lithiophilic composite skeleton (CLCS) as a loader of deposited Li metal to enhance the electrochemical performance and improve the lifespan of Li metal batteries. Specifically, numerous lithiophilic groups (pyridinic $\mathrm{N}$, pyrrolic $\mathrm{N}$, and $\mathrm{Cu}_{\mathrm{x}} \mathrm{N}$ sites) in the CLCS exhibit strong binding to Li atoms, resulting in improved homogeneous dispersion of $\mathrm{Li}$ ions and subsequent dendrite-free Li deposition. Furthermore, stepwise Li deposition and stripping can be conducted during the galvanostatic Li charging/discharging process, suppressing concentrated $\mathrm{Li}$ nucleation while avoiding aggressive $\mathrm{Li}$ growth. Consequently, both asymmetric and symmetric cells based on CLCS exhibit a prolonged cycling lifetime and a decreased voltage polarization. Furthermore, full cells composed of CLCS@Li anodes deliver a stable cycling plot and high capacity retention when coupled with common cathode materials $\left(\mathrm{LiFePO}_{4}\right.$ and $\left.\mathrm{SeS}_{2}\right)$.

\section{Experimental Section}

\subsection{Materials}

Commercial copper foam (CF) substrate with the thickness of $0.5 \mathrm{~mm}$ was provided by KunShan GuangJiaYuan new materials Co., Ltd. N, N-dimethylformamide (DMF) solvent and poly(acrylonitrile) $(\mathrm{Mw}=150,000)$ were obtained from J\&K Scientific and Sinopharm Chemical Reagent Co., Ltd. .

\subsection{Material Synthesis}

Commercial CF substrates were cleaned and placed in a muffle furnace and annealed at $600{ }^{\circ} \mathrm{C}$ for $2 \mathrm{~h}$ in the presence of air. Subsequently, the black oxidized CF substrates were immersed in a pre-prepared poly(acrylonitrile) solution (8 $\mathrm{wt} \%$ ) for $10 \mathrm{~min}$ and then transferred to an oven for drying. The CLCS was prepared by annealing the dried mixture at $600{ }^{\circ} \mathrm{C}$ for $2 \mathrm{~h}$ in a $\mathrm{H}_{2} / \mathrm{Ar}(5 / 95, \mathrm{v} / \mathrm{v})$ atmosphere. The heating rate was set at $2{ }^{\circ} \mathrm{C} \mathrm{min}{ }^{-1}$.

\subsection{Material Characterization}

The morphologies of various samples were observed and analyzed using a scanning electron microscopy (Hitachi SU1510) and transmission electron microscopy (JEM2010F). The components of the CLCS were characterized using X-ray diffraction (XRD, Rigaku D/max-2550 V). Raman spectra and in situ Raman spectra were obtained using a Raman spectrometer (Renishaw inVia plus). Related in situ optical images were conducted by Smartroom 5 
(Zeiss). The XPS measurements were conducted on a Thermo Scientific K-Alpha instrument.

\subsection{Electrochemical Measurements}

Each coin cell (CR 2032) based on CF or CLCS electrodes was assembled in an argon-filled glove box with $\mathrm{H}_{2} \mathrm{O}$ and $\mathrm{O}_{2}$ content lower than $0.1 \mathrm{ppm}$. The Coulombic efficiency was determined using a specific amount of Li metal plated on the bare CF and CLCS, which was then stripped away through the voltage of $1 \mathrm{~V}$. For galvanostatic charge/discharge testing, CF@Li or CLCS@Li electrodes loaded

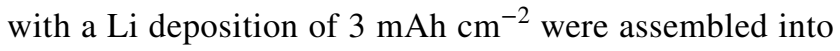
symmetrical cells. Specially, the specific capacity of the CLCS@Li composite anode in symmetry and full cells is $\sim 1600 \mathrm{mAh} \mathrm{g}^{-1}$. Celgard 2400 and $1 \mathrm{M}$ LiTFSI in DOL/ $\operatorname{DME}(1: 1, \mathrm{v} / \mathrm{v})$ with $2 \% \mathrm{LiNO}_{3}$ additive were chosen as the separator and electrolyte, respectively, in asymmetrical and symmetrical cells. The amount of selected electrolyte was controlled at $40 \mathrm{uL}$ per coin cell. The full cells assembled using commercial $\mathrm{LiFePO}_{4}$ (LFP) and selenium sulfide $\left(\mathrm{SeS}_{2}\right)$ cathodes. The $\mathrm{SeS}_{2}$ cathodes were fabricated by preparing a mixture of weighed cathode powder, conductive carbon black, and polyvinylidene fluoride (PVDF) binder in a mass ratio of 8:1:1 dispersed in N-methyl-2-pyrrolidone (NMP) solvent and casting it on Al foil. Subsequently, the $\mathrm{Al}$ foil with slurry was dried in a vacuum oven at $120^{\circ} \mathrm{C}$ for $10 \mathrm{~h}$. The dried foil loaded with an LFP (areal mass: $\sim 6 \mathrm{mg} \mathrm{cm}^{-2}$ ) or $\mathrm{SeS}_{2}$ (areal mass: $\sim 1.5 \mathrm{mg} \mathrm{cm}^{-2}$ ) cathode was assembled into a full cell with a specific $\mathrm{Li}$ metal anode. $1 \mathrm{M} \mathrm{LiPF}_{6}$ in EC/DEC $(1: 1, \mathrm{v} / \mathrm{v})$ and $1 \mathrm{M}$ LiTFSI in DOL/DME $(1: 1, \mathrm{v} / \mathrm{v})$ with $2 \% \mathrm{LiNO}_{3}$ additive were used as the electrolytes of the full cells composed of LFP and $\mathrm{SeS}_{2}$, respectively. Furthermore, the amount of electrolyte used was fixed at $40 \mu \mathrm{L}$ per coin cell. The voltage window of 2.5-4.2 V was applied to the LilLFP cell. Similarly, the $\mathrm{LilSeS}_{2}$ full cell was controlled between 1.7 and $2.8 \mathrm{~V}$. The electrochemical performance was measured in a LAND-CT2001 test system.

\subsection{Theoretical Calculation}

The constructed model of CLCS composite was optimized by the $\mathrm{DMol}^{3}$ module of Materials Studio (MS) software, in which the functional was chosen as Perdew-Wang (PWC) in local density approximation (LDA).

\section{Results and Discussion}

\subsection{Preparation and Characterizations of CLCS}

A facile oxidization-immersion-reduction method was explored to produce a novel functional current collector. Figure 1a illustrates the preparation of the CLCS in detail. Initially, metallic copper foam (CF) was oxidized in air and transformed into the fragile and black copper oxide $(\mathrm{CuO})$ skeleton. Subsequently, the free-standing $\mathrm{CuO}$ skeleton was immersed in an as-prepared commercial-grade polyacrylonitrile (PAN) solution for organic coating. Finally, CLCS was obtained through a reduction process at $600{ }^{\circ} \mathrm{C}$ in a $\mathrm{H}_{2}$ and $\operatorname{Ar}(5 \% / 95 \%, \mathrm{v} / \mathrm{v})$ atmosphere from a $\mathrm{CuO}$ composite skeleton coated with PAN with the color of the products changing from black to brown. As illustrated in Fig. 1b, the different morphology observed following Li deposition on bare CF and CLCS highlights the difference in the lithiophilicity between these two substrates. Furthermore, uniform Li nucleation and growth can be achieved in the CLCS where $\mathrm{Li}$ ions are attracted to lithiophilic $\mathrm{N}$-containing groups (pyridinic $\mathrm{N}$, pyrrolic $\mathrm{N}$, and $\mathrm{Cu}_{\mathrm{x}} \mathrm{N}$ sites) during the Li plating process and then reduced on the CLCS. These excellent lithiophilic sites can suppress dendritic Li growth from the CLCS, and the resultant uniform Li deposition can enhance working safety, improve the electrochemical performance, and prolong the cycling life of cells. Conversely, an inhomogeneous distribution of metallic Li grains occurs in the CF substrate owing to its poor lithiophilicity at the initial $\mathrm{Li}$ nucleation stage. The continuous Li deposition would transform the plated Li metal into large bulks with various forms such as Li dendrites, resulting in unnecessary electrolyte consumption and the internal short circuit of the working battery.

As displayed in Fig. S1, the bare CF exhibited a shiny color and a smooth surface. After calcination in air, the oxidized $\mathrm{CF}$ turned black owing to the formation of $\mathrm{CuO}$ (Fig. 1a). Figure 2a-c displays the related scanning electron microscopy (SEM) images of the oxidized CF which anchors several vertical $\mathrm{CuO}$ nanoneedles with flat surfaces. However, these unique nanoneedles could not maintain their structure during the calcination process in a 


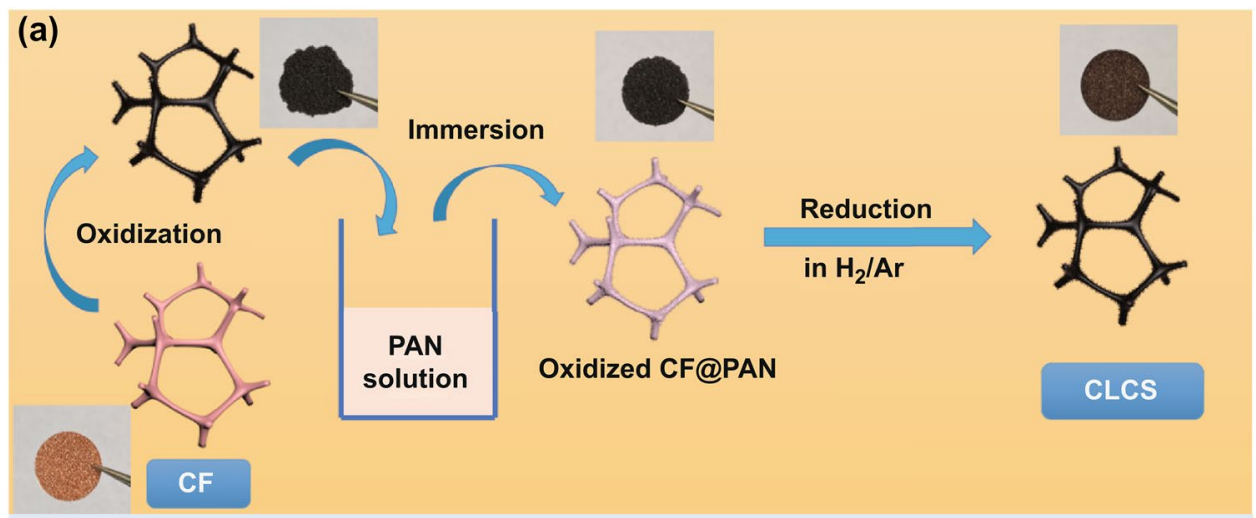

(b)
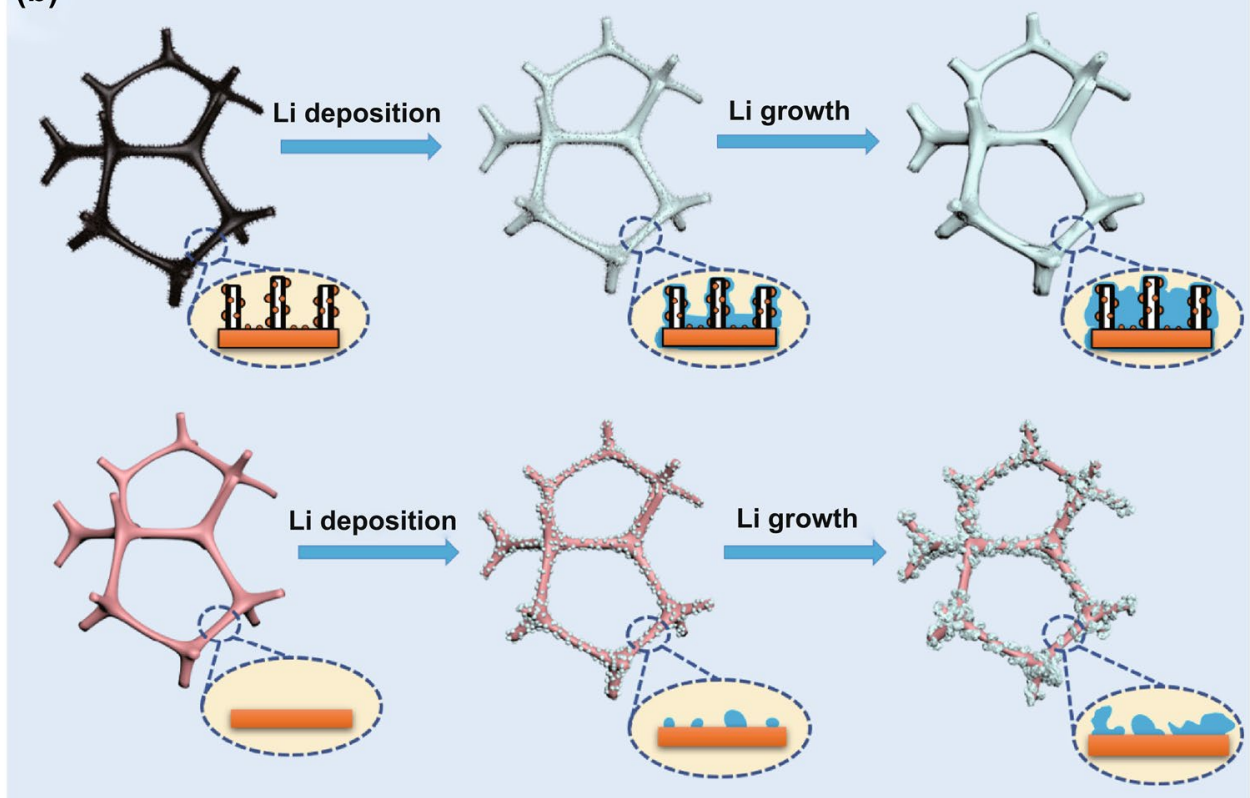

Fig. 1 a Schematic diagrams for the synthetic process of CLCS. b Different Li deposition and growth behaviors in bare CF and CLCS

mixed gas atmosphere $\left(\mathrm{H}_{2} / \mathrm{Ar}: 5 \% / 95 \%\right.$, v/v). The reduced $\mathrm{CF}$ following the calcination process illustrated in Fig. $\mathrm{S} 2$ indicates the absence of the original nanoneedles and pores in the skeleton. Conversely, massive nanoneedles were retained in the CLCS with the perfect protection of the coated carbon layer. As shown in Fig. 2d-f, several thin nanoneedles are decorated with $\mathrm{Cu}$ nanoparticles in the CLCS. The SEM image at higher magnification (Fig. S3) illustrates the surface of the CLCS being covered with massive $\mathrm{N}$-doped carbon-coated $\mathrm{Cu}$ nanoparticles, which promotes uniform Li deposition. Figure $2 \mathrm{~g}$ displays the transmission electron microscopy (TEM) image of a pristine $\mathrm{CuO}$ nanoneedle with a smooth surface and a solid structure, in agreement with Fig. 2c. However, as shown in Fig. 2h, a noticeable hollow space was observed in a nanoneedle of the CLCS, which could improve the electrolyte transport. Furthermore, there are some internal regular $\mathrm{Cu}$ nanoparticles formed from the decomposition and reduction of pristine $\mathrm{CuO}$ nanoneedles in addition to the external nanoparticles embedded in the nanoneedles. The elemental distributions of $\mathrm{C}, \mathrm{N}$, and $\mathrm{Cu}$ displayed in Fig. 2i are detected accurately and observed in the vertical nanoneedles using energy-dispersive X-ray spectroscopy, illustrating the structural uniformity of the CLCS. Furthermore, the distinctive distributions of the aforementioned elements are in accordance with the selected detection area in the SEM image (Fig. S4). This result substantiates the uniform distribution of $\mathrm{C}, \mathrm{N}$, and 

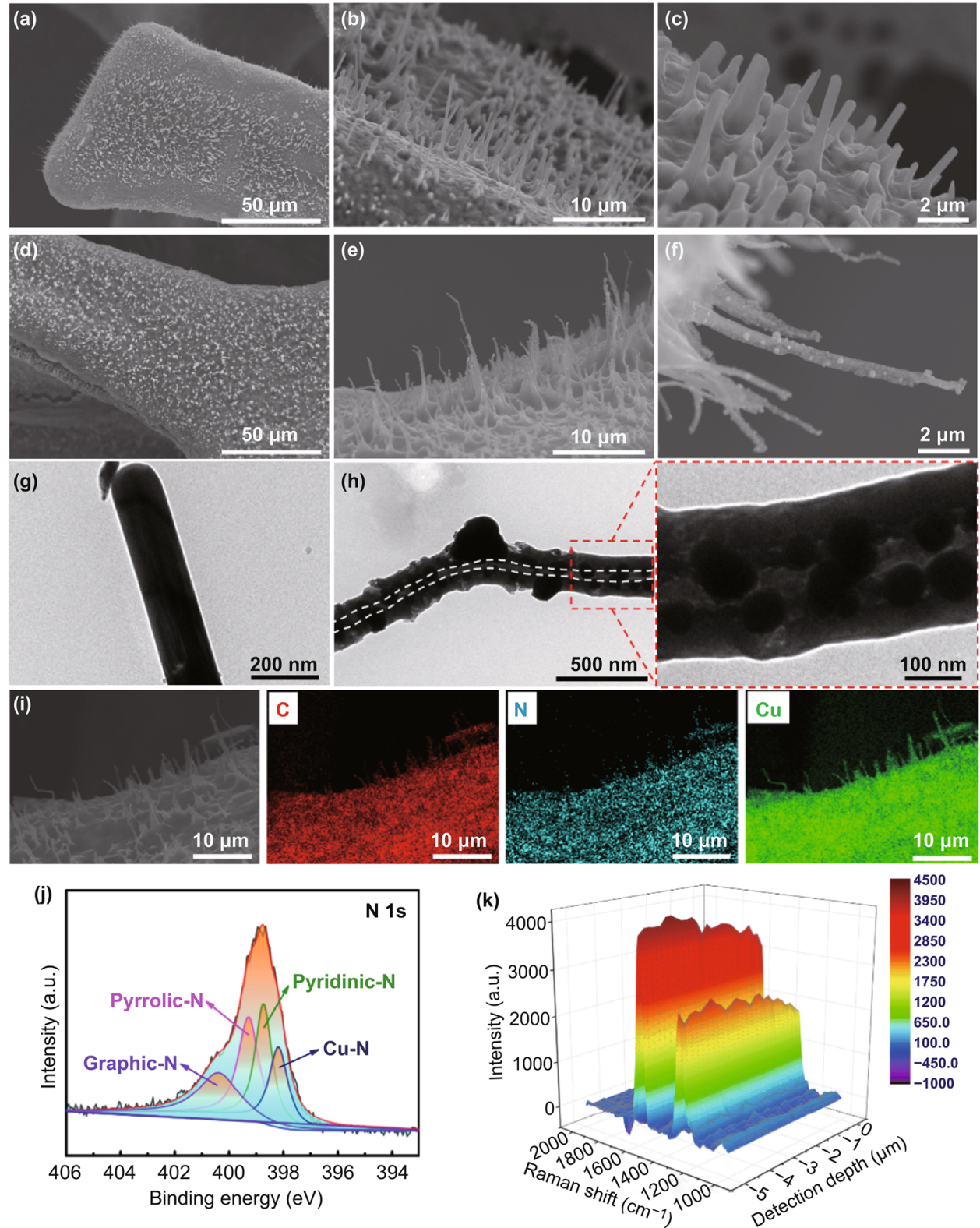

Fig. 2 SEM images of a-c oxidized CF and d-f CLCS. TEM images of $\mathbf{g}$ oxidized CF and $\mathbf{h}$ CLCS. $\mathbf{i}$ EDS mapping containing C, N and Cu element for CLCS. j XPS survey spectra (N 1s) and $\mathbf{k}$ Raman spectra at different depths of CLCS

$\mathrm{Cu}$ elements in the CLCS. Figure S5 illustrates the XRD patterns of the CLCS. The peak at $23^{\circ}$ was assigned to the amorphous carbon, and three typical characteristic peaks belonging to $\mathrm{Cu}$ metal (JCPDS No. 04-0836) were identified. As depicted in Fig. 2j, the XPS results were used to validate the structural composition of the CLCS. The common graphic N (399.31 eV), pyrrolic N (399.31 eV), pyridinic $\mathrm{N}(398.75 \mathrm{eV})$, and notably the $\mathrm{Cu}-\mathrm{N}$ site $(398.21 \mathrm{eV})$ are observed in the $\mathrm{N} 1 \mathrm{~s}$ spectrum of the CLCS [40-43]. The isolated Raman spectrum of the CLCS displays a high degree of graphitization (Fig. S6). Additionally, the Raman spectra at different depths of the CLCS shown in Fig. 2k illustrate the slow gradual increase and eventual stabilization of the intensity of the D-band $\left(1320.71 \mathrm{~cm}^{-1}\right)$ and G-band $\left(1579.97 \mathrm{~cm}^{-1}\right)$ indicating interactions between the $\mathrm{N}$-doped carbon and the reduced $\mathrm{Cu}$ nanoparticles, which affect the structural uniformity. 


\subsection{Li Deposition and Stripping in CLCS}

The remarkable lithiophilicity of the CLCS was explored using density functional theory (DFT) to calculate the binding energy and charge density of Li atoms adsorbed on preferential functional groups $(\mathrm{Cu}$, graphite, pyridinic
$\mathrm{N}$, pyrrolic $\mathrm{N}$, and $\mathrm{Cu}_{\mathrm{x}} \mathrm{N}$ sites). As shown in Figs. $3 \mathrm{a}$ and $\mathrm{S} 7$, the binding energies of $\mathrm{Li}$ atoms and graphite and $\mathrm{Li}$ atoms and $\mathrm{Cu}$ were calculated to be 1.599 and $2.597 \mathrm{eV}$, respectively. This demonstrates the poor adsorption of $\mathrm{Li}$ atoms and the increased possibility of Li deposition and accumulation. However, the binding energy of the Li atom
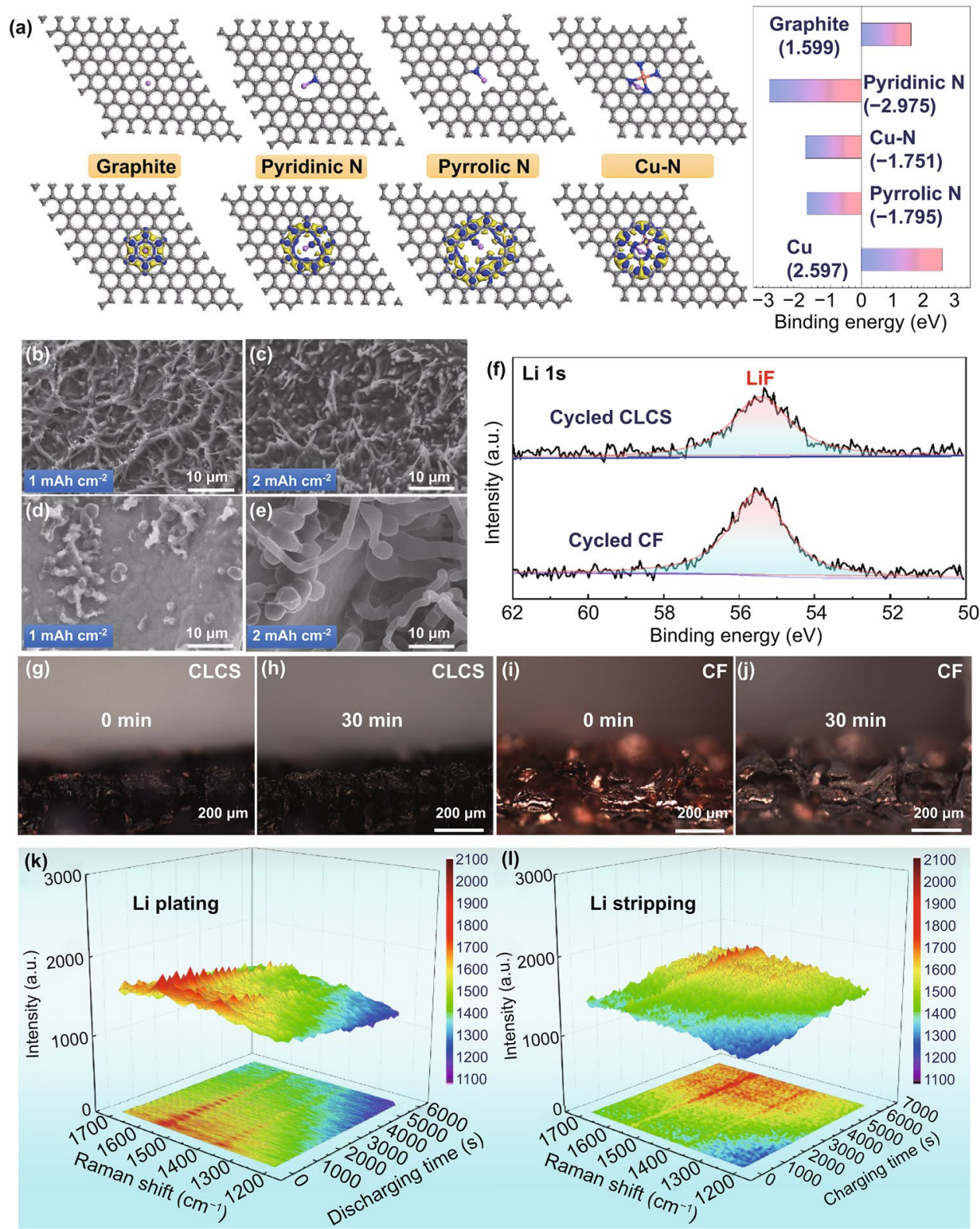

Fig. 3 a Density functional theory calculations on the adsorption energy between $\mathrm{Li}$ atoms and graphite, pyridinic $\mathrm{N}$, pyrrolic $\mathrm{N}$ and $\mathrm{Cu}-\mathrm{N}$ site. Moreover, values of related adsorption energy for these groups are calculated. SEM images of CLCS loading with Li deposition of $\mathbf{b} 1 \mathrm{mAh}$ $\mathrm{cm}^{-2}$ and $\mathbf{c} 2 \mathrm{mAh} \mathrm{cm}^{-2}$. SEM images of CF plating with metallic Li of $\mathbf{d} 1 \mathrm{mAh} \mathrm{cm}^{-2}$ and e $2 \mathrm{mAh} \mathrm{cm}^{-2}$. f XPS survey spectra of CLCS and CF electrode after 50 cycles. In situ optical observation of CLCS at the discharging time of $\mathbf{g} 0 \mathrm{~min}$ and $\mathbf{h} 30 \mathrm{~min}$. In situ optical images of CF at the discharging time of $\mathbf{i} 0 \mathrm{~min}$ and $\mathbf{j} 30 \mathrm{~min}$. In situ Raman spectra of CLCS at $\mathbf{k} \mathrm{Li}$ plating and $\mathbf{l} \mathrm{Li}$ stripping process 
to pyridinic $\mathrm{N}(-2.976 \mathrm{eV})$, pyrrolic $\mathrm{N}(-1.795 \mathrm{eV})$, and $\mathrm{Cu}-\mathrm{N}$ sites $(-1.751 \mathrm{eV})$ indicates a strong $\mathrm{Li}$ adsorption and effective Li distribution. Furthermore, the difference in the charge densities of the adsorbed $\mathrm{Li}$ on these aforementioned groups helps in determining their different lithiophilicity. The electron accumulation and reduction are represented by the blue and yellow regions, respectively. A lower charge transfer was observed for $\mathrm{Li}$ adsorbed on $\mathrm{Cu}$ and graphite, demonstrating the weak bond between $\mathrm{Li}$ and $\mathrm{Cu}$ as well as $\mathrm{Li}$ and graphite. Conversely, a significant degree of charge transfer was observed for the $\mathrm{Li}$ adsorbed on pyridinic $\mathrm{N}$, pyrrolic $\mathrm{N}$, and $\mathrm{Cu}-\mathrm{N}$ sites. This further corroborates the strong bond formed between $\mathrm{Li}$ and $\mathrm{N}$-containing functional groups while highlighting the impressive lithiophilicity of the CLCS. SEM images of the CLCS and CF loaded with different areal capacities of metallic $\mathrm{Li}$ are presented to evaluate the effect of guiding uniform Li deposition and suppressing the generation of $\mathrm{Li}$ dendrites. The surface of the CLCS without any dendrites was found to be smoother in comparison with the original morphology as Li was plated on the CLCS (Fig. 3b, c). These magnified images of the CLCS loaded with metallic $\mathrm{Li}$ indicate that the cucumberlike surface of the CLCS gradually disappears as the Li deposition capacity increases from 1 to $3 \mathrm{mAh} \mathrm{cm}^{-2}$, eventually flattening (Fig. S8a-c). In the process of Li stripping, the continuous stripping of Li metal from the CLCS causes the reappearance of a cucumber-like surface, indicating ordered, stepwise Li deposition and stripping (Fig. S8d-f). However, the Li deposition on $\mathrm{CF}$ exhibits a highly disordered distribution and an uncontrolled formation of dendritic Li due to the poor lithiophilicity of CF (Fig. 3d, e). Notably, irregular $\mathrm{Li}$ bulks and pronounced $\mathrm{Li}$ dendrites were observed from magnified partial details in the SEM images (Fig. S9). Additionally, the morphology of cycled CLCS and CF after 50 cycles indicated residual $\mathrm{Li}$ on the $\mathrm{CF}$ skeleton as compared to the residual-free CLCS (Fig. S10). Figure $3 f$ displays the XPS spectra of the cycled CLCS and CF to assess the surface components. As illustrated by the $\mathrm{Li} 1 \mathrm{~s}$ spectra, $\mathrm{LiF}$ $(55.48 \mathrm{eV})$ was detected in the cycled CF and CLCS, which can be ascribed to the decomposition of the electrolyte on the surface of the electrodes [44]. Furthermore, once the $\mathrm{Li}$ dendrites break the SEI, excess electrolyte consumption is inevitable for the formation of fresh SEI which culminates in the rapid failure of the cell.

An in situ optical micrograph test was carried out to observe the innate $\mathrm{Li}$ deposition behavior and further investigate the remarkable lithiophilicity of the CLCS. Figure $3 \mathrm{~g}$ displays the initial state of the CLCS before the $\mathrm{Li}$ is plated on the skeleton. A homogeneous color change in the substrate was observed when metallic Li was plated on the CLCS for $30 \mathrm{~min}$ because of the favorable Li distribution and uniform Li deposition (Fig. 3h). As shown in Fig. 3i, bare CF exhibits a shiny color before the Li plating on the skeleton. However, the majority of the bare $\mathrm{CF}$ was not covered by metallic Li after continuous Li deposition for $30 \mathrm{~min}$ and was still exposed to the electrolyte (Fig. 3j), further corroborating its poor lithiophilicity compared to CLCS. Although the superior lithiophilicity of CLCS has been confirmed, the priority of Li deposition in this carbon-based material needs further examination with defects in the carbon playing an important role in storing $\mathrm{Li}$ ions. Hence, in situ Raman spectra were investigated as an appropriate probing method to determine the priority of the $\mathrm{Li}$ deposition behavior. Figure S11 displays the discharging and charging profiles of the CLCS at a current density of $1 \mathrm{~mA} \mathrm{~cm}{ }^{-2}$ with an areal capacity of $3 \mathrm{mAh} \mathrm{cm}^{-2}$ in an assembled battery. As highlighted in Fig. 3k, the intensity of the D-band and G-band of the CLCS gradually decreased with the increase in Li plating time. Notably, the intensity of the D-band dropped faster than that of the G-band, indicating that metallic $\mathrm{Li}$ was preferentially deposited at the defects of CLCS [45]. Additionally, the intensity of the G-band was found to be enhanced before the D-band during the inverse charging process (Fig. 31). The results of in situ Raman spectroscopy clearly demonstrate that metallic $\mathrm{Li}$ was first deposited on the defects, and gradually covered the surface of the CLCS. Hence, the stepwise Li deposition and stripping in the CLCS could avoid concentrated nucleation and the growth of metallic Li, effectively suppressing the generation of Li dendrites and the excess consumption of the electrolyte.

\subsection{Electrochemical Performances of CLCS-based Li Metal Batteries}

The excellent lithiophilicity should enhance the electrochemical performance of the asymmetric and symmetric cells based on the CLCS. The reversibility of the Li plating/stripping performance on the substrate is an essential factor for evaluating the formation of Li dendrites or dead $\mathrm{Li}$ in the current collector of Li metal anodes. Figure S12 
shows the Nyquist plots of asymmetric cells based on bare CF and CLCS electrodes. The CLCS electrode delivers a higher transfer impedance of $54.7 \Omega$ than that (37.3 $\Omega$ ) of CF due to the existence of nitrogen-doped carbon coating, which is less conductive than $\mathrm{Cu}$. Moreover, Nyquist plot of CLCS electrodes after 50 cycles can be observed in Fig. S13. Because of the interface stabilization, transfer impedance has been decreased to $21.2 \Omega$ from the initial state $(54.7 \Omega)$. This reduced transfer impedance is beneficial to promoting the uniform Li deposition. As shown in
Fig. 4a, the asymmetric cells consisting of CLCS electrodes exhibit comparatively stable CE plots. Specifically, CLCS electrodes demonstrate a high CE value of $97.8 \%$ for 700 cycles at $1 \mathrm{~mA} \mathrm{~cm}{ }^{-2}, 97.5 \%$ for 400 cycles at $3 \mathrm{~mA} \mathrm{~cm}{ }^{-2}$, and $98.1 \%$ for 200 cycles at $5 \mathrm{~mA} \mathrm{~cm}^{-2}$, respectively. Conversely, the bare $\mathrm{CF}$ electrode maintains a shorter cycling lifespan with a quick CE decay because of the generation of Li dendrites. The CLCS displays a superior CE performance to that of CF even when cycled at a high areal capacity of 3 $\mathrm{mAh} \mathrm{cm}^{-2}$ (Fig. S14). Figure $4 \mathrm{~b}$ displays the voltage profiles
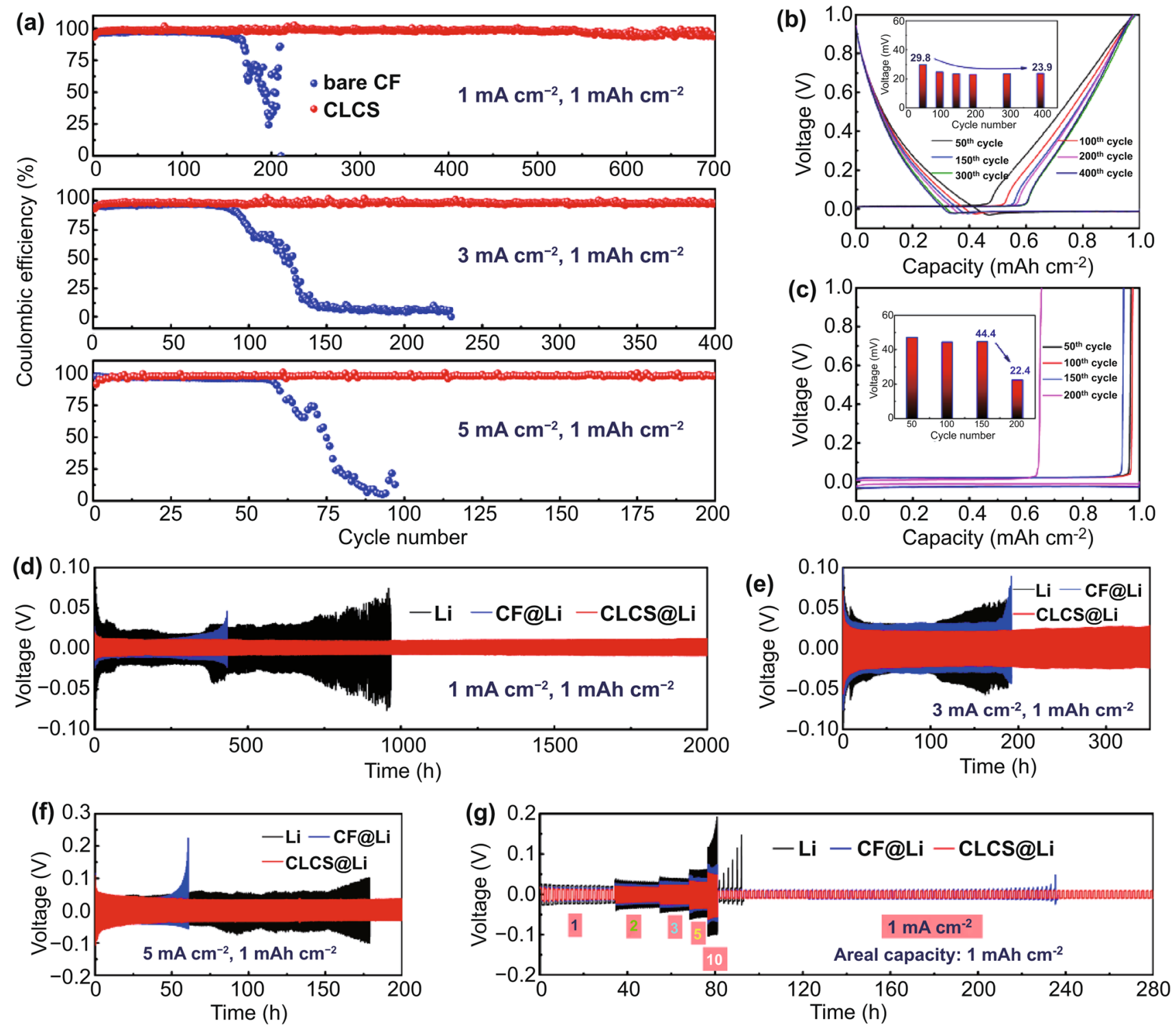

Fig. 4 a Coulombic efficiency performance of bare CF and CLCS at 1, 3, and $5 \mathrm{~mA} \mathrm{~cm}^{-2}$ with a fixed capacity of $1 \mathrm{mAh} \mathrm{cm}^{-2}$. Voltage-capacity plots at different cycles and corresponding voltage hysteresis of $\mathbf{b}$ CLCS and $\mathbf{c}$ CF. Voltage-time profiles in symmetric cells composing of Li, CF@Li and CLCS@Li electrodes at $\mathbf{d} 1 \mathrm{~mA} \mathrm{~cm}^{-2}, \mathbf{e} 3 \mathrm{~mA} \mathrm{~cm}^{-2}$ and $\mathbf{f} 5 \mathrm{~mA} \mathrm{~cm}^{-2}$. $\mathbf{g}$ Rate performance with a cycling capacity of $1 \mathrm{mAh} \mathrm{cm}^{-2}$ 
of the CLCS at different cycles at $1 \mathrm{~mA} \mathrm{~cm}^{-2}$ with a plating capacity of $1 \mathrm{mAh} \mathrm{cm}^{-2}$, which demonstrate that the CLCS maintains a stable and high CE as the cycle number increases. Additionally, the voltage polarization was found to decrease from $29.8 \mathrm{mV}$ at the 50th cycle to $23.9 \mathrm{mV}$ at the 400th cycle, which may result from the gradual stabilization of the electrode interface. Apart from the continuous capacity loss of stripped Li metal, the voltage profiles at different cycles of the bare $\mathrm{CF}$ are displayed in Fig. $4 \mathrm{c}$ and indicate a rapid voltage polarization drop from $44 \mathrm{mV}$ at the 150 th cycle to $22.4 \mathrm{mV}$ at the 200th cycle, indicating an internal short circuit caused by dendritic Li. Symmetric cells based on CLCS@Li were assembled to determine the effect of improving the cycling stability and avoiding the generation of Li dendrites on the electrochemical performance. The CLCS@LilCLCS@Li demonstrated an extremely stable voltage curve with an ultra-long cycling lifespan of $2000 \mathrm{~h}$ compared to the fluctuating voltage curves of LilLi and CF@LilCF@Li cells (Fig.4d). Furthermore, even after 1000 cycles, a relatively small voltage hysteresis of $20.3 \mathrm{mV}$ was maintained (Fig. S15). The CLCS@LilCLCS@Li cells exhibited a long-term cycling performance with enhanced stability when cycled at a high current density of $3 \mathrm{~mA} \mathrm{~cm}^{-2}$ and $5 \mathrm{~mA} \mathrm{~cm}^{-2}$, similar to that at $1 \mathrm{~mA} \mathrm{~cm}^{-2}$ (Fig. 4e, f). However, the CF@LilCF@Li cell experienced a rapid increase in voltage polarization after less than $200 \mathrm{~h}$ at $3 \mathrm{~mA} \mathrm{~cm}{ }^{-2}$ and at $60 \mathrm{~h}$ at $5 \mathrm{~mA} \mathrm{~cm}{ }^{-2}$ because of the uncontrolled growth of $\mathrm{Li}$ dendrites and excessive consumption of the electrolyte. The fragile SEI on the metallic $\mathrm{Li}$ foil was easily broken due to the large volume expansion of the plated Li metal, which diminishes the electrochemical performance of the LilLi symmetric cell. Moreover, the CLCS@LilCLCS@Li cell exhibits an impressive rate performance with slight fluctuations in voltage polarization. Notably, a symmetrical cell containing CLCS@Li exhibited a relatively low voltage hysteresis of approximately $115 \mathrm{mV}$ at $10 \mathrm{~mA} \mathrm{~cm}$ c $^{-2}$ (Fig. $4 \mathrm{~g}$ ). These results indicate that CLCS with superior lithiophilicity can improve the electrochemical performance and extend the cycling life of working batteries.

A CLCS@Li anode was coupled to a commercial $\mathrm{LiFePO}_{4}$ (LFP) cathode and assembled into a full cell to determine its potential in practical Li metal batteries. For the CLCS@Li anode, metallic Li of $3 \mathrm{mAh} \mathrm{cm}^{-2}$ should be electroplated onto the skeleton. Additionally, the specific capacity of the CLCS@Li composite anode was measured to be around $1600 \mathrm{mAh} \mathrm{g}^{-1}$. The specific capacity of the unique anode is much superior to other types of anodes with $\mathrm{Cu}$ current collector. High density of $\mathrm{Cu}$ does have a negative effect on the specific capacity of composite anode. In order to better realize the practical application of high-energy Li metal batteries, it is essential to explore more light-weight current collectors. As displayed in Fig. 5a, CLCS@LilLFP demonstrates a comparatively stable capacity plot with a high $\mathrm{CE}$ value at a current density of $0.2 \mathrm{~A} \mathrm{~g}^{-1}$. A high specific capacity of $110.1 \mathrm{mAh} \mathrm{g}^{-1}$ was obtained by the CLCS@LilLFP full cell even after cycling 600 cycles. Additionally, a superior capacity retention ratio of $88.8 \%$ (compared to the initial specific capacity of $124 \mathrm{mAh} \mathrm{g}^{-1}$ ) indicates the suppressed formation of $\mathrm{Li}$ dendrites and dead $\mathrm{Li}$, in contrast to the rapid capacity loss with sharp fluctuations for CF@LilLFP and LilLFP. Figure $5 \mathrm{~b}$ displays the rate performance of full cells based on Li, CF@Li, and CLCS@Li anodes. The CLCS@LilLFP cell displayed the highest specific capacity at various current densities compared to those of the LilLFP and CF@LilLFP full cells. The high capacity delivery and excellent capacity preservation exhibited by the CLCS@LilLFP cell following the charge-discharge test at higher current density further demonstrate its improved electrochemical performance. Figure $5 \mathrm{c}$ displays the galvanostatic charge-discharge profiles at different current densities of CLCS@LilLFP. The exceptional interfacial reaction kinetics increases the voltage polarization by approximately $30 \mathrm{mV}$ from 0.05 to $1 \mathrm{~A} \mathrm{~g}^{-1}$. The CLCS@ $\mathrm{Li}$ anode was also coupled with a selenium disulfide $\left(\mathrm{SeS}_{2}\right)$ cathode to assemble a different full cell to gauge its applicability. As shown in Fig. 5d, the electrochemical performances of $\mathrm{LilSeS}_{2}, \mathrm{CF} @ \mathrm{LilSeS}_{2}$, and CLCS@ $\mathrm{LilSeS}_{2}$ cells were measured at a high current density of $1 \mathrm{~A} \mathrm{~g}^{-1}$. The CLCS@ $\mathrm{LilSeS}$ cell exhibited the slowest capacity decay and the highest capacity retention (66.3\%) after 500 cycles among these full cells, while the initial cell activation was at $0.2 \mathrm{~A} \mathrm{~g}^{-1}$ for 3 cycles. A comparable $\mathrm{LilSeS}_{2}$ cell has similar capacity decay during the first 50 cycles, benefiting from the initially stable electrode interface formed on the $\mathrm{Li}$ foil. The interface is then broken down by the growing $\mathrm{Li}$ dendrites owing to the uneven Li deposition, unavoidably leading to additional electrolyte consumption. The specific capacity of the $\mathrm{LilSeS}_{2}$ cell decreases rapidly and continuously. This could be because the high amounts of dendritic Li originally on the anode, with the exception of the fragile CF@Li anode interface, are transferred onto the 
(a)

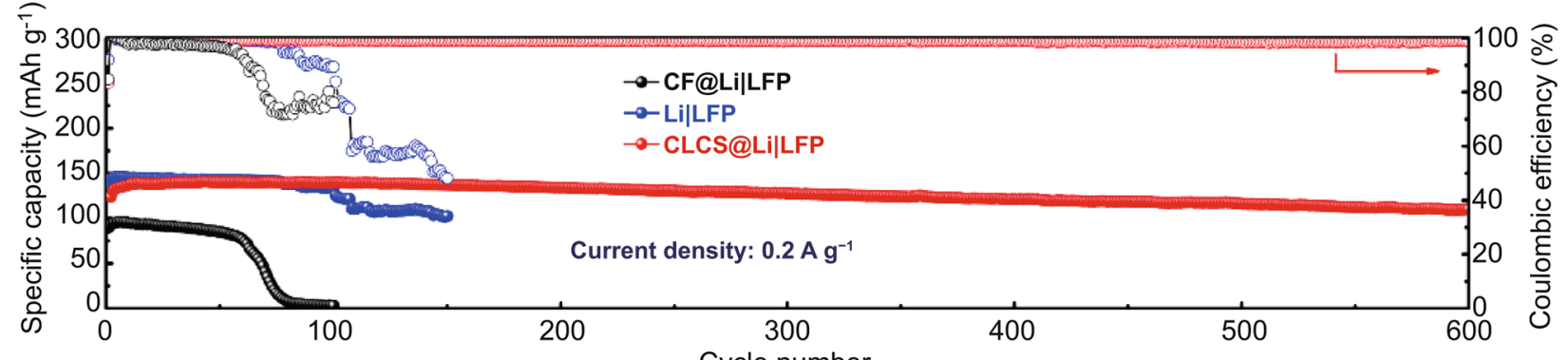

(b)

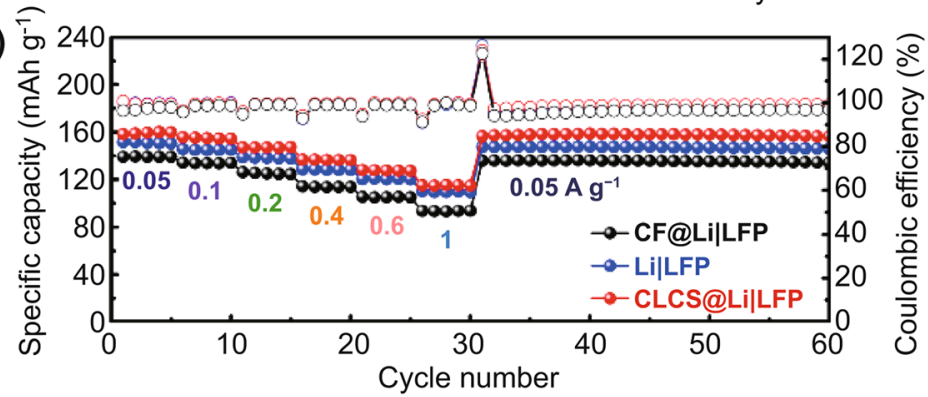

(d)

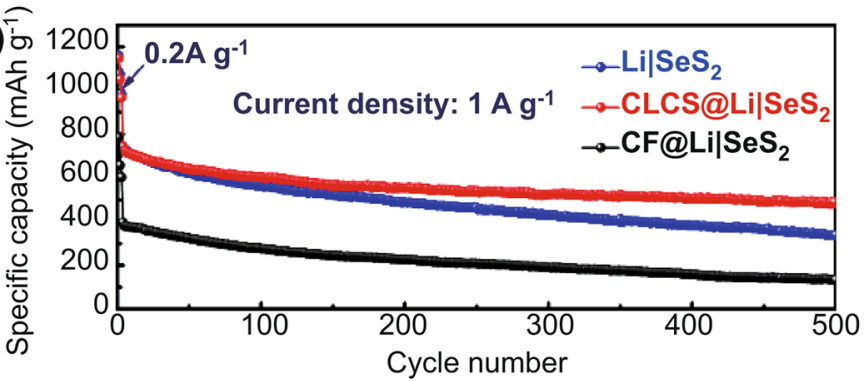

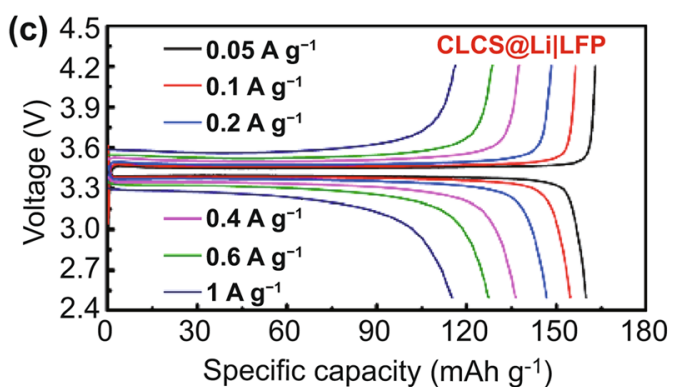

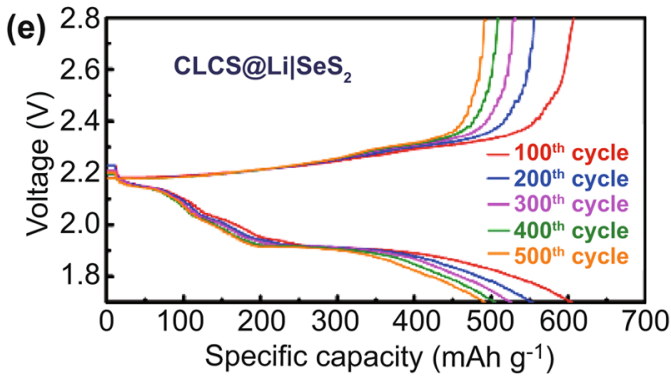

Fig. 5 a Cycling performance of LilLFP, CF@LilLFP and CLCS@LilLFP full cells at a current density of $0.2 \mathrm{~A} \mathrm{~g}^{-1}$. b Rate performance at various current densities from 0.05 to $1 \mathrm{~A} \mathrm{~g}^{-1}$ and $\mathbf{c}$ related galvanostatic charge-discharge profiles. d SeS 2 -based full cells coupled with Li, CF@ $\mathrm{Li}$ and CLCS@Li anode at $1 \mathrm{~A} \mathrm{~g}^{-1}$. e Corresponding galvanostatic charge-discharge profiles at different cycles

inactive dead Li during the continuous charge-discharge process, resulting in the extremely low capacity. Figure 5e exhibits the galvanostatic charge-discharge profiles at different cycles of the CLCS@ $\mathrm{LilSeS}_{2}$ cell. This cell demonstrates a high specific capacity $\left(491.8 \mathrm{mAh} \mathrm{g}^{-1}\right)$ even after cycling for 500 cycles with minor voltage polarization fluctuations between the 100th and the 500th cycle, in sharp contrast to the significant changes in the voltage polarization of the $\mathrm{LilSeS}_{2}$ and $\mathrm{CF} @ \mathrm{LilSeS}_{2}$ cells (Figs. $\mathrm{S} 16$ and S17). The electrochemical performances and thorough discussion on the cells employing CLCS-based Li anodes have also been proved the excellent lithiophilicity and effectively suppressed formation of Li dendrites, highlighting their potential as efficient and realistic Li metal batteries.

\section{Conclusion}

In summary, we report the synthesis of a unique free-standing cucumber-like lithiophilic composite skeleton to function as a container for deposited Li metal through a facile fabrication method. The pyridinic N, pyrrolic N, and several $\mathrm{Cu}_{\mathrm{x}} \mathrm{N}$ sites provide excellent lithiophilicity to facilitate strong binding to the $\mathrm{Li}$ atoms, guide uniform $\mathrm{Li}$ deposition and suppress the generation of Li dendrites. Furthermore, stepwise Li deposition and stripping on the CLCS, as determined by in situ Raman spectra, alleviate the concentrated and uncontrolled Li nucleation and growth. The cells consisting of CLCS electrodes benefit from these advantages and display prolonged cycling life and improved electrochemical performance. Additionally, they demonstrate an 
extremely high CE performance of $97.3 \%$ after 700 cycles in an asymmetrical cell along with an ultra-long and stable lifespan of $2000 \mathrm{~h}$ for a symmetrical cell at $1 \mathrm{~mA} \mathrm{~cm}^{-2}$ with a deposition capacity of $1 \mathrm{mAh} \mathrm{cm}^{-2}$. The full cells based on the CLCS@Li anodes assembled with $\mathrm{LiFePO}_{4}$ and $\mathrm{SeS}_{2}$ cathodes maintain a high reversible capacity of $110.1 \mathrm{mAh} \mathrm{g}^{-1}$ after 600 cycles in the CLCS@LilLFP cell and $491.8 \mathrm{mAh} \mathrm{g}^{-1}$ after 500 cycles in the CLCS@ $@ \mathrm{LilSeS}_{2}$ cell. The successful construction and application of CLCS provide a template for dendrite-free and high-capacity $\mathrm{Li}$ metal batteries.

Acknowledgements This work is well supported by National Natural Science Foundation of China (52073170, 21975154), Shanghai Municipal Education Commission (Innovation Program (2019-0107-00-09-E00021) and Innovative Research Team of High-level Local Universities in Shanghai. The authors also acknowledge Lab for Microstructure, Instrumental Analysis \& Research Center, Shanghai University, for their help on materials characterization. Moreover, the authors thank High Performance Computing Center of Shanghai University, and Shanghai Engineering Research Center of Intelligent Computing System (No. 19DZ2252600) for the assistance of computing resources and technical support.

Open Access This article is licensed under a Creative Commons Attribution 4.0 International License, which permits use, sharing, adaptation, distribution and reproduction in any medium or format, as long as you give appropriate credit to the original author(s) and the source, provide a link to the Creative Commons licence, and indicate if changes were made. The images or other third party material in this article are included in the article's Creative Commons licence, unless indicated otherwise in a credit line to the material. If material is not included in the article's Creative Commons licence and your intended use is not permitted by statutory regulation or exceeds the permitted use, you will need to obtain permission directly from the copyright holder. To view a copy of this licence, visit http://creativecommons.org/licenses/by/4.0/.

Supplementary Information The online version contains supplementary material available at https://doi.org/10.1007/ s40820-021-00687-3.

\section{References}

1. D. Lin, Y. Liu, Y. Cui, Reviving the lithium metal anode for high-energy batteries. Nat. Nanotechnol. 12, 194 (2017). https://doi.org/10.1038/nnano.2017.16

2. W. Xu, J. Wang, F. Ding, X. Chen, E. Nasybulin et al., Lithium metal anodes for rechargeable batteries. Energy Environ. Sci. 7, 513 (2014). https://doi.org/10.1039/C3EE40795K

3. J. Goodenough, Y. Kim, Challenges for rechargeable Li batteries. Chem. Mater. 22, 587 (2010). https://doi.org/10.1021/ cm901452z
4. Z. Ghazi, Z. Sun, C. Sun, F. Qi, B. An et al., Key aspects of lithium metal anodes for lithium metal batteries. Small 15, 1900687 (2019). https://doi.org/10.1002/smll.201900687

5. P. Bai, J. Li, F. Brushett, M.Z. Bazant, Transition of lithium growth mechanisms in liquid electrolytes. Energy Environ. Sci. 9, 3221 (2016). https://doi.org/10.1039/C6EE01674J

6. P. Albertus, S. Babinec, S. Litzelman, Newman, Status and challenges in enabling the lithium metal electrode for highenergy and low-cost rechargeable batteries. Nat. Energy 3, 16 (2018). https://doi.org/10.1038/s41560-017-0047-2

7. G. Umeda, E. Menke, M. Richard, K. Stamm, F. Wudl et al., Protection of lithium metal surfaces using tetraethoxysilane. J. Mater. Chem. 21, 1593 (2011). https://doi.org/10.1039/C0JM0 2305A

8. D. Chen, S. Huang, L. Zhong, S. Wang, M. Xiao et al., In situ preparation of thin and rigid COF film on Li anode as artificial solid electrolyte interphase layer resisting li dendrite puncture. Adv. Funct. Mater. 30, 1907717 (2020). https://doi.org/ 10.1002/adfm.201907717

9. E. Kazyak, K. Wood, N. Dasgupta, Improved cycle life and stability of lithium metal anodes through ultrathin atomic layer deposition surface treatments. Chem. Mater. 27, 6457 (2015). https://doi.org/10.1021/acs.chemmater.5b02789

10. S. Tung, S. Ho, M. Yang, R. Zhang, N. Kotov et al., A dendrite-suppressing composite ion conductor from aramid nanofibers. Nat. Commun. 6, 6152 (2015). https://doi.org/10. 1038/ncomms 7152

11. J. Kim, D. Kim, S. Joo, B. Choi, A. Cha et al., Hierarchical chitin fibers with aligned nanofibrillar architectures: a nonwoven-mat separator for lithium metal batteries. ACS Nano 11, 6114 (2017). https://doi.org/10.1021/acsnano.7b02085

12. W. Luo, L. Zhou, K. Fu, Z. Yang, J. Wan et al., A thermally conductive separator for stable Li metal anodes. Nano Lett. 15, 6149 (2015). https://doi.org/10.1021/acs.nanolett.5b02432

13. W. Liu, Y. Mi, Z. Weng, Y. Zhong, Z. Wu et al., Functional metal-organic framework boosting lithium metal anode performance via chemical interactions. Chem. Sci. 8, 4285 (2017). https://doi.org/10.1039/C7SC00668C

14. F. Ding, W. Xu, G. Graff, J. Zhang, M. Sushko et al., Dendritefree lithium deposition via self-healing electrostatic shield mechanism. J. Am. Chem. Soc. 135, 4450 (2013). https://doi. org/10.1021/ja312241y

15. H. Yang, L. Yin, H. Shi, K. He, H. Cheng et al., Suppressing lithium dendrite formation by slowing its desolvation kinetics. Chem. Commun. 55, 13211 (2019). https://doi.org/10.1039/ C9CC07092C

16. Q. Liu, Y. Xu, J. Wang, B. Zhao, Z. Li et al., Sustained-release nanocapsules enable long-lasting stabilization of Li anode for practical Li-metal batteries. Nano-Micro Lett. 12, 176 (2020). https://doi.org/10.1007/s40820-020-00514-1

17. J.N. Chazalviel, Electrochemical aspects of the generation of ramified metallic electrodeposits. Phys. Rev. A 42, 7355 (1990). https://doi.org/10.1103/PhysRevA.42.7355

18. C. Monroe, J. Newman, The impact of elastic deformation on deposition kinetics at lithium/polymer interfaces. 
J. Electrochem. Soc. 152, A396 (2005). https://doi.org/10. 1149/1.1850854

19. C. Brissot, M. Rosso, J. Chazalviel, P. Baudry, S. Lascaud et al., In situ study of dendritic growth in lithium/PEO-salt/ lithium cells. Electrochim. Acta 43, 1569 (1998). https://doi. org/10.1016/S0013-4686(97)10055-X

20. W. Huang, Y. Yu, Z. Hou, Z. Liang, Y. Zheng et al., Dendritefree lithium electrode enabled by graphene aerogels with gradient porosity. Energy Storage Mater. 33, 329 (2020). https:// doi.org/10.1016/j.ensm.2020.08.032

21. H. Shi, M. Yue, C. Zhang, Y. Dong, P. Lu et al., 3D Flexible, Conductive, and recyclable $\mathrm{Ti}_{3} \mathrm{C}_{2} \mathrm{~T}_{\mathrm{x}}$ MXene-melamine foam for high-areal-capacity and long-lifetime alkali-metal anode. ACS Nano 14, 8678 (2020). https://doi.org/10.1021/acsnano. 0c03042

22. R. Zhang, X. Cheng, C. Zhao, H. Peng, J. Shi et al., Conductive nanostructured scaffolds render low local current density to inhibit lithium dendrite growth. Adv. Mater. 28, 2155 (2016). https://doi.org/10.1002/adma.201504117

23. S. Matsuda, Y. Kubo, K. Uosaki, S. Nakanishi, Lithium-metal deposition/dissolution within internal space of CNT 3D matrix results in prolonged cycle of lithium-metal negative electrode. Carbon 119, 119 (2017). https://doi.org/10.1016/j.carbon. 2017.04.032

24. X. Zhang, R. Lv, A. Wang, W. Guo, X. Liu et al., MXene aerogel scaffolds for high-rate lithium metal anodes. Angew. Chem. Int. Ed. 57, 15028 (2018). https://doi.org/10.1002/anie. 201808714

25. M. Chen, J. Zheng, O. Sheng, C. Jin, H. Yuan et al., Sulfurnitrogen co-doped porous carbon nanosheets to control lithium growth for a stable lithium metal anode. J. Mater. Chem. A 7, 18267 (2019). https://doi.org/10.1039/C9TA05684J

26. X. Chen, X. Chen, T. Hou, B. Li, X. Cheng et al., Lithiophilicity chemistry of heteroatom-doped carbon to guide uniform lithium nucleation in lithium metal anodes. Sci. Adv. 5, eaau7728 (2019). https://doi.org/10.1126/sciadv.aau7728

27. F. Pei, A. Fu, W. Ye, J. Peng, X. Fang et al., Robust Lithium metal anodes realized by lithiophilic 3D porous current collectors for constructing high-energy lithium-sulfur batteries. ACS Nano 13, 8337 (2019). https://doi.org/10.1021/acsnano. 9b03784

28. J. Luan, Q. Zhang, H. Yuan, Z. Peng, Y. Tang et al., Sn layer decorated copper mesh with superior lithiophilicity for stable lithium metal anode. Chem. Eng. J. 395, 124922 (2020). https://doi.org/10.1016/j.cej.2020.124922

29. C. Yang, Y. Yao, S. He, H. Xie, E. Hitz et al., Ultrafine silver nanoparticles for seeded lithium deposition toward stable lithium metal anode. Adv. Mater. 29, 1702714 (2017). https:// doi.org/10.1002/adma.201702714

30. H. Ye, Z. Zheng, H. Yao, S. Liu, T. Zuo et al., Guiding uniform Li plating/stripping through lithium-aluminum alloying medium for long-life Li metal batteries. Angew. Chem. Int. Ed. 58, 1094 (2019). https://doi.org/10.1002/anie.201811955

31. P. Xue, S. Liu, X. Shi, C. Sun, C. Lai et al., A hierarchical silver-nanowire-graphene host enabling ultrahigh rates and superior long-term cycling of lithium-metal composite anodes. Adv. Mater. 30, 1804165 (2018). https://doi.org/10. 1002/adma.201804165

32. B. Yu, T. Tao, S. Mateti, S. Lu, Y. Chen et al., Nanoflake arrays of lithiophilic metal oxides for the ultra-stable anodes of lithium-metal batteries. Adv. Funct. Mater. 28, 1803023 (2018). https://doi.org/10.1002/adfm.201803023

33. M. Zhu, B. Li, S. Li, Z. Du, Y. Gong et al., Dendrite-free metallic lithium in lithiophilic carbonized metal-organic frameworks. Adv. Energy Mater. 8, 1703505 (2018). https:// doi.org/10.1002/aenm.201703505

34. S. Wu, Z. Zhang, M. Lan, S. Yang, J. Cheng et al., Lithiophilic $\mathrm{Cu}-\mathrm{CuO}-\mathrm{Ni}$ hybrid structure: advanced current collectors toward stable lithium metal anodes. Adv. Mater. 30, 1705830 (2018). https://doi.org/10.1002/adma.201705830

35. K. Yan, Z. Lu, H. Lee, F. Xiong, P. Hsu et al., Selective deposition and stable encapsulation of lithium through heterogeneous seeded growth. Nat. Energy 1, 16010 (2016). https://doi.org/ 10.1038/nenergy.2016.10

36. N. Li, Q. Ye, K. Zhang, H. Yan, C. Shen et al., Normalized lithium growth from the nucleation stage for dendrite-free lithium metal anodes. Angew. Chem. Int. Ed. 58, 1 (2019). https://doi.org/10.1002/anie.201911267

37. X. Chen, B. Li, C. Zhao, R. Zhang, Q. Zhang, Synergetic coupling of lithiophilic sites and conductive scaffolds for dendritefree lithium metal anodes. Small Methods 4, 1900177 (2020). https://doi.org/10.1002/smtd.201900177

38. Y. He, H. Xu, J. Shi, P. Liu, Z. Tian et al., Polydopamine coating layer modified current collector for dendrite-free Li metal anode. Energy Storage Mater. 23, 418 (2019). https://doi.org/ 10.1016/j.ensm.2019.04.026

39. T. Liu, J. Ge, Y. Xu, L. Lv, W. Sun et al., Organic supramolecular protective layer with rearranged and defensive Li deposition for stable and dendrite-free lithium metal anode. Energy Storage Mater. 32, 261 (2020). https://doi.org/10.1016/j.ensm. 2020.07.007

40. T. Wang, X. Liu, X. Zhao, P. He, C. Nan et al., Regulating uniform Li plating/stripping via dual-conductive metal-organic frameworks for high-rate lithium metal batteries. Adv. Funct. Mater. 30, 2000786 (2020). https://doi.org/10.1002/adfm. 202000786

41. P. Ren, Q. Li, T. Song, Y. Yang, Facile fabrication of the $\mathrm{Cu}-$ $\mathrm{N}-\mathrm{C}$ catalyst with atomically dispersed unsaturated $\mathrm{Cu}-\mathrm{N}_{2}$ active sites for highly efficient and selective glaser-hay coupling. ACS Appl. Mater. Interfaces 12, 27210 (2020). https:// doi.org/10.1021/acsami.0c05100

42. X. Zhao, S. Xia, X. Zhang, Y. Pang, F. Xu et al., Highly lithiophilic copper-reinforced scaffold enables stable Li metal anode. ACS Appl. Mater. Interfaces 13, 20240 (2021). https:// doi.org/10.1021/acsami.1c04735

43. Y. Guan, N. Li, Y. Li, L. Sun, Y. Gao et al., Two dimensional ZIF-derived ultra-thin $\mathrm{Cu}-\mathrm{N} / \mathrm{C}$ nanosheets as high performance oxygen reduction electrocatalysts for high-performance Zn-air batteries. Nanoscale 12, 14259 (2020). https://doi.org/ 10.1039/D0NR03495A 
44. T. Liu, J. Hu, C. Li, Y. Wang, Unusual conformal Li plating on alloyable nanofiber frameworks to enable dendrite suppression of Li metal anode. ACS Appl. Energy Mater. 2, 4379 (2019). https://doi.org/10.1021/acsaem.9b00573
45. H. Li, D. Chao, B. Chen, X. Chen, C. Chuah et al., Revealing principles for design of lean-electrolyte lithium metal anode via in situ spectroscopy. J. Am. Chem. Soc. 142, 2012 (2020). https://doi.org/10.1021/jacs.9b11774 